\title{
KINETIC OF ASCORBIC ACID DISSOLUTION IN LOCAL POMEGRANATE JUICES
}

\author{
Rajab Ibrahim Hameed DOSKI
}

Department of Medical Lab Technology, Duhok Technical Inistitute, Duhok Polytechnic University, Kurdistan Region-Iraq. (rajab.ibrahim@dpu.edu.krd)

\begin{abstract}
:
This research was conducted to examine the impact of storage house time and storage house temperatures on ascorbic acid dissolution in pomegranate juice. The juice of pomegranate stored at the temperatures 15,25 and $35 \mathrm{C} 0$ for four months. Outcomes noted that in the case of rising temperature and period storage house let to reducing the ascorbic acid content. The results of ascorbic acid dissolution kinetic parameter showed that the order of the reaction is first and there was an increasing in rate constant $(\mathrm{K})$ in the case of increasing the storage house temperature. Also, the half time decreased with increasing the temperature of storage house. It was found that the shelf life of all samples decreased with increasing the storage house temperatures and storage house period.
\end{abstract}

KEYWORDS: Pomegranate, Ascorbic acid, Kinetic, Activation energy, Dissolution.

\section{INTRODUCTION}

Pomegranate (Punica granatum Lythraceae) fruits are important fruits in Kurdistan Region-Iraq as they are an excellent source of vitamins, dietary fiber, and minerals and provide flavor, aroma, and texture to the delights of eating. The pomegranate fruits are usually consumed fresh or consumed as a juice. pomegranate holds numerous combinations of substances that have anti-cancer and antioxidant features that are helpful in disease risk reduction, therefore, there is an increasing interest in this fruit. (Nweze, Abdulganiyu, \& Erhabor, 2015). Vitamin-C is a vital nutrient for humans and animals. The antioxidant properties and acting as cofactor for at least eight enzymes made it as a highly influencing element in the biological systems (Doski, 2019). As Vitamin-C deficiency leads to scurvy in humans, it is necessary to introduce it as a supplement in the diet to overcome the disease. The structure of pomegranate juice depends on the nature of cultivar, environmental and postharvest factors, and storage house and processing factors (Mditshwa, Fawole, Al-Said, Al-Yahyai, \& Opara, 2013; R. Vijayaraje, S. Krishi, \& Vidyalaya, 2011). The dissolution of ascorbic acid in storehouse is the basic problem of nutritional loss of quality in the juices which also define their shelf life. This matter is very important to the juice makers to accurately prepare and save the juice under suitable circumstances, therefore the consumer would get the maximum benefit of the vitamin $\mathrm{C}$ content in the juices. It is essential to know the ascorbic acid dissolution resistance by studying the kinetics of ascorbic acid loss in pomegranate juices throughout storage house. The kinetic resistance has been used to define vitamin C dissolution (A. Holcroft, Deirdre; \& Gil, 1998). The purpose of this research is to estimate the kinetics dissolution of vitamin $\mathrm{C}$ in freshly home-made pomegranate juices at storage house in 15,25 and 35 temperature through 4 months. The dissolution of vitamin $\mathrm{C}$ occurs with both aerobic and anaerobic manners. The release of vitamin $\mathrm{C}$ following the anaerobic status is not yet resolved because of its complexity (A. Holcroft et al., 1998). Vitamin C is tense to damage when the outcome is reduced to storage house conditions. destruction of ascorbic acid is raised by long storage house, high temperatures, low relative moisture, physical harm, and chilling damage (Paul \& Ghosh, 2012).

\section{MATERIAL AND METHODS}

\subsection{Sample preparation:}

Fresh pomegranate(has the common names in different languages which are Anar, granda, grandier,Hinar and Ruman) of approximately equal in size and weight were collected from a garden in the city of Zakho, throughout the harvest period in September 2018. The products were carried to the chemical laboratories at Duhok technical institute. They were cleaned and sliced in two halves and hand-squeezed for juice. The Juice clarification was conducted by a regular kitchen filter.

The juice was warmed to $70 \mathrm{C}^{0}$ (Centigrade degree)) for $20 \mathrm{sec}$ then moderated to $20 \mathrm{C}^{0}$ and stocked in $300 \mathrm{~mL}$ containers (clear or dark green) for 4 months at the $15,25,35 \mathrm{C}^{0}$ storage house. The specimen containers were underfilled, finishing in approximately 5-10 $\mathrm{mL}$ of headspace.

\subsection{TSS\%:}

The TSS\% was prepared as Brix by a temperature controlled refractometer (CARL ZEISS JENA, Model. 711849, Germany).

\subsection{Titratable Acidity:}

$10 \mathrm{ml}$ of the the juice were blended with $200 \mathrm{~mL}$ of purified water then boiled for 1 hour. Then the mix was cooled and filtered. The filtrate mix was carried to a $250 \mathrm{~mL}$ volumetric container. as an indicator, $10 \mathrm{~mL}$ of the filtrate was titrated with $0.1 \mathrm{M}$ of $\mathrm{NaOH}$ using a $1 \%$ phenolphthalein solution. The outcomes were proved as \% citric acid (Lugwisha Esther Hellen, Fabian Christina, \& Othman, 2014). All measurements were performed in triplicate and the average marks were noted. $\%$ total acidity $=\left(\mathrm{ml} \mathrm{NaOH}^{*} \mathrm{~N}^{*}\right.$ eq. wt of citric acid $) / \mathrm{ml}$ of sample) $) * 100$

2.4. $\mathrm{pH}$.The $\mathrm{pH}$ was measured with a $\mathrm{pH}$ meter (HI 98107) 2.5. Ascorbic Acid:

$5 \mathrm{ml}$ of juice were mixed with $25 \mathrm{~mL}$ of $5 \%$ metaphosphoric acid liquid. The blend was filtered within a Whitman No. 42 filter paper. The excess was then swabbed with $5 \%$ metaphosphoric acid until the entire amount of the obtained filtrate was $50 \mathrm{ml}$. 
The filtrate was then centrifuged at 2000 r.p.m for $20 \mathrm{~min}$, then $10 \mathrm{~mL}$ of the pure filtrate was pipetted into a conical flask and titrated against a $0.025 \%$ 2,6-dichlorophenol-indophenol reagent. The titration was done in triplicate and the standard values were recorded. The $0.025 \%$ of 2,6- dichlorophenolindophenol reagent was standardized using a standard ascorbic acid solution as described by AOAC (Ojukwu \& Nwobi, 2017).

\subsection{Statistically analysis:}

The facts were statistically examined with SPSS 2003, and the average verifying were done according to Duncan's multiple range examination at level $1 \%$.

\subsection{Kinetic Study:}

kinetic research determined the rate constant, half-time and the activation potential for vitamin C. For standard constant the methods was used by (Ojukwu \& Nwobi, 2017).

For rate constant(k) Calculate from the decline straight line of the relationship between Ln of Ascorbic acid concentration $\mathrm{Ln}(\mathrm{A})$ and storage house time(months), for Activation energy(Ea.) calculate from the equation - $\mathrm{Ea}=$ slope* $\mathrm{R} * 2.303$ Where $\mathrm{R}=$ gas constant

$=1.99 \mathrm{cal}$, for Correlation coefficient (R2) Calculate from the decline straight line of the relationship between $\mathrm{Ln}$ of the rate constant $(\mathrm{k})$ and inverted of absolute temperature, while the Half time calculate with the equation $\mathrm{T} 1 / 2=\mathrm{Ln}(2) / \mathrm{k}$

Where $\mathrm{K}=$ rata constant,

Temperature coefficient $\left(\mathrm{Q}_{10}\right)$ calculate with the equation

$\mathrm{Q} 10=(\mathrm{k} 2 / \mathrm{k} 1) 10 /(\mathrm{T} 2-\mathrm{T} 1)$

Where $\mathrm{K} 2 \mathrm{~K} 1$ =rate constant at $\mathrm{t} 2 \mathrm{t} 1$

$\mathrm{T} 2 \mathrm{~T} 1=$ Absolute temperature

Shelf life calculate with the equation

Expire $=\mathrm{e}-(\mathrm{s} / \mathrm{T}+\mathrm{I}-\mathrm{Ln}(\mathrm{p} / 100))$

Where $\mathrm{T}=$ kelvin temperature

$\mathrm{I}=$ intercept

$\mathrm{S}=$ slope

$\mathrm{P}=$ present of residual ascorbic acid

$\mathrm{e}=$ euller number

$=2.718$

And we use new Microsoft Excel worksheet for application this equation.

\section{RESULTS AND DISCUSSION}

The test results on proximate forms TSS, acidity, $\mathrm{pH}$ and ascorbic acid content of pomegranate (Punica granatum L.) are listed in Table 1. All proceeds are the average returns of triplicate determinations.

\subsection{TSS\%:}

The fresh juice contains $14 \%$ total soluble solids. table 1. This result is also within the range of values extracted. as reported by (N. Matei et al., 2008).

\subsection{Titratable Acidity:}

Acidity in fruits is an essential factor in defining maturity. Numerous fruits have huge acidity at the beginning of the season, making them unacceptable to consumers even though they meet minimum sugar standards.

So fermentation performs a vital role in the flavor, tone, and microbial balance of the fruit juice. A drop in titratable acidity was seen throughout storage house ripening of pomegranate fruits. This reduction of acidity could be because of the utilization of constituent acids in the respiratory methods (Hasnaoui et al., 2011). This performance as well described by (Paul \& Ghosh, 2012) for Saudi Arabian pomegranate fruits. The observed titratable acidity values for pomegranate fruit during storage house -ripening are presented in Table 1 . At the time of picking, the pomegranate fruits had $0.62 \%$ citric acid .
This value is within the range of $0.35 \%$ to $3.36 \%$ for Iranian pomegranate fruits reported by this value of titratable acidity in this study make the pomegranate acceptable to consumers.

\section{3. $\mathrm{pH}$ :}

The PH value of fresh juice is 1.52 . This result is shown in table 1 . This result is also within the range of values extracted. as reported by (Othman \& Mbogo, 2009).

Table 1. Proximate composition (TSS, acidity, PH and ascorbic acid) content of pomegranate (punica granatum $L$.)

\begin{tabular}{|l|l|}
\hline Parameters & result \\
\hline TSS(Brix) & 14 \\
\hline Titratable acidity $(\%)$ & 0.62 \\
\hline $\mathrm{pH}$ & 1.52 \\
\hline $\begin{array}{l}\text { Ascorbic acid }(\mathrm{mg} / 100 \\
\text { ml) }\end{array}$ & 14 \\
\hline
\end{tabular}

\subsection{Ascorbic Acid:}

Ascorbic acid is a water-soluble vitamin, crystalline mixture with a solid reducing feature. Ascorbic acid holds similar health advantages as commonly occurring vitamin C.fruits and vegetables are the strongest sources of ascorbic acid (vitamin C).

(Table 2) and Fig(1) show content ascorbic acid of pomegranate juice stored at 20,30, $40 \mathrm{C}^{0}$ for four months. The dissolution of vitamin $\mathrm{C}$ in fresh pomegranate juices was examined in the phases of Ascorbic acid (AA) combination. depending on the storage house temperature, gradually the ascorbic acid in all pomegranate juices was slowly reduced. (Aguilar, Ramırez, Garrote, \& Vázquez, 2002).

The impact of storehouse temperature on the ascorbic acid waste in the fresh juices could be seen in Fig(1). The ascorbic acid waste was reduced when the juice was put at the $15 \mathrm{C}^{0}$. it was approved by the prior study that low-temperature storehouse could reduce the dissolution flow of ascorbic acid. (Nkwocha et al., 2018) and (Awagu, Ekanem, Kolo, \& Adamu, 2017).

Table 2. Effect of storage house on ascorbic acid content at different Temperatures.*

\begin{tabular}{|c|c|c|c|}
\hline \multirow{2}{*}{$\begin{array}{c}\text { Storage house } \\
\text { time(month) }\end{array}$} & \multicolumn{3}{|c|}{ Temperature $\left(\mathbf{c}^{\mathbf{0}}\right)$} \\
\cline { 2 - 4 } & 15 & 25 & 35 \\
\hline 0 & $14 \mathrm{a} \mathrm{A}$ & $14 \mathrm{a} \mathrm{A}$ & $14 \mathrm{a} \mathrm{A}$ \\
\hline 1 & $11 \mathrm{a} \mathrm{B}$ & $9 \mathrm{ab} \mathrm{B}$ & $6 \mathrm{~b} \mathrm{~B}$ \\
\hline 2 & $10 \mathrm{a} \mathrm{B}$ & $7 \mathrm{ab} \mathrm{BC}$ & $4 \mathrm{~b} \mathrm{BC}$ \\
\hline 3 & $9 \mathrm{a} \mathrm{BC}$ & $6 \mathrm{a} \mathrm{C}$ & $3 \mathrm{~b} \mathrm{CD}$ \\
\hline 4 & $7 \mathrm{a} \mathrm{C}$ & $5 \mathrm{a} \mathrm{C}$ & $2 \mathrm{~b} \mathrm{D}$ \\
\hline
\end{tabular}

- Different small letters in the row means the values differ significantly $\mathrm{p}<0.01$ according to Duncan as a result of storage house temperatures.

- Different capital letters in the Colum means the values differ significantly $\mathrm{p}<0.01$ according to Duncan as a result of period storage house temperatures .

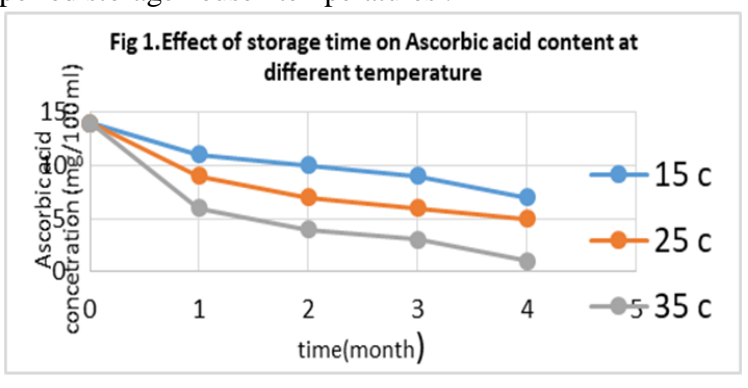




\subsection{Kinetic}

The structure of the development in Ln of ascorbic acid dissolution with the period produced direct line Fig(2). Therefore the dissolution of ascorbic acid in this research was represented by a first-order reflection.

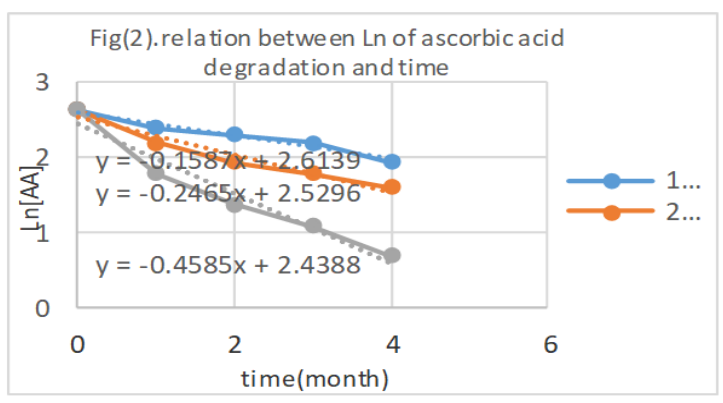

The rate constant(K) for ascorbic acid dissolution were different at low and high temperatures (table 3 ) which calucate from Fig (2).

The results indicated that the rate constant $(\mathrm{K})$ of ascorbic acid dissolution was higher at elevated temperatures, because the rise in temperature increase the reaction rate of ascorbic acid loss. Also we saw in the same table the half time $t_{1 / 2}$ (the time requisite to react half initial concentration of substrate) of ascorbic acid loss decrease with increasing the temperature of storage house ,4.368 month at $15 \mathrm{C}^{0}$ and 1.512 month at $35 \mathrm{C}^{0}$. Activation energy Ea.(k.cal/mole) were determined as a conclusion of a gas constant $(\mathrm{R})$ and the slope of the chart accomplished by considering Ln $\mathrm{k}$ versus $1 / \mathrm{T}$ (Fig 3). The activation reaction of ascorbic acid dissolution of pomegranate juice in this research was $21.54 \mathrm{k} . c a l /$ mole table (3).

The association coefficient (R2) was measured as a result of a gas constant(R) and the slope of the diagram accomplished by considering $\mathrm{Ln} \mathrm{k}$ versus 1/T (Fig 3).

The correlation coefficient (R2) (table 3 ) $>0.9$ proves that the dissolution of ascorbic acid in this research supports a firstorder reflection at storehouse temperatures $15,25,35 \mathrm{C} 0$ sequentially.

This results agree with other studies (RODRIGUEZ, DURAN, MURIEL, \& FRANCO, 2012) and (Rahmawati \& Bundjali, 2012). In the same table we saw the temperature coefficient $\left(\mathrm{Q}_{10}\right)$ is 1.55 when the storage house temperature rise from $15-25 \quad \mathrm{C}^{0}$ and 1.86 when the storage house temperature rise from $25-35 \mathrm{C}^{0}$, that mean in increasing the temperature the molecule of ascorbic acid take more of heat energy and increase dissolution of ascorbic acid, The results above are also within the scope of values described by (Robertson \& Samaniego, 1986) and (Laing, Schlueter, \& Labuza, 1978).

Table 3. Rate constant(K), activation energy(Ea.), correlation coefficient $\left(\mathrm{R}^{2}\right)$, Half-time, temperature coefficient $(\mathrm{Q} 10)$ of ascorbic acid dissolution at different temperatures.

\begin{tabular}{|c|c|c|c|c|c|c|}
\hline \multirow[b]{2}{*}{$\begin{array}{l}\text { Temperat } \\
\text { ures } \mathbf{C}^{0}\end{array}$} & \multirow[b]{2}{*}{$\begin{array}{l}\text { Rate } \\
\text { consta } \\
\text { nt }(K) \\
\text { Month } \\
-1\end{array}$} & \multirow{2}{*}{$\begin{array}{l}\text { Activati } \\
\text { on } \\
\text { energy( } \\
\text { Ea) } \\
\text { k.cal/m } \\
\text { ol }\end{array}$} & \multirow[b]{2}{*}{$\mathbf{R}^{2}$} & \multirow{2}{*}{$\begin{array}{l}\text { Half } \\
- \\
\text { time } \\
\text { t/2 } \\
\text { mont } \\
\text { hs }\end{array}$} & \multicolumn{2}{|c|}{$\mathrm{Q}_{10}$} \\
\hline & & & & & $\begin{array}{l}15- \\
25 \\
C^{0}\end{array}$ & $\begin{array}{l}25 \\
- \\
35 \\
C^{0}\end{array}$ \\
\hline 15 & 0.1587 & \multirow{3}{*}{21.54} & \multirow{3}{*}{$\begin{array}{l}0.9 \\
86\end{array}$} & 4.4 & \multirow{3}{*}{$\begin{array}{l}1.5 \\
5\end{array}$} & \multirow{3}{*}{$\begin{array}{l}1.8 \\
6\end{array}$} \\
\hline 25 & 0.2456 & & & 2.8 & & \\
\hline 35 & 0.4585 & & & 1.5 & & \\
\hline
\end{tabular}

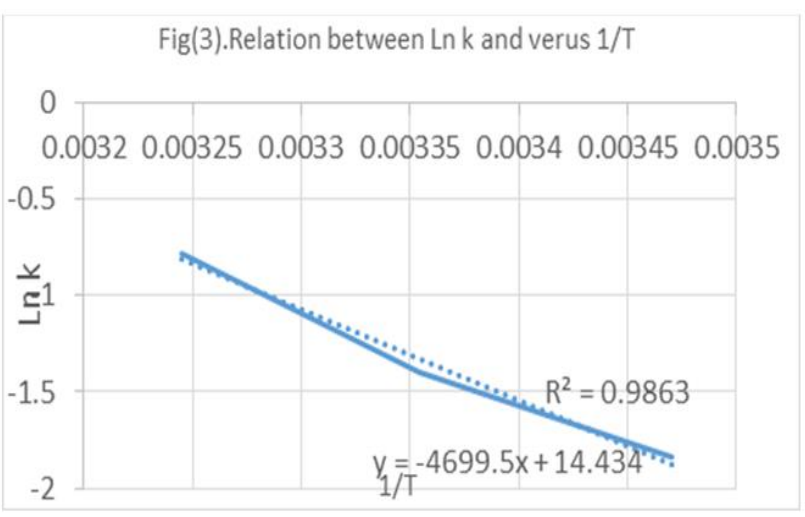

Table 4. Considering the limit for shelf life of inductive to ascorbic acid dissolution.

\begin{tabular}{|c|c|}
\hline $\begin{array}{c}\text { Temperature } \\
\mathbf{C}^{\mathbf{0}}\end{array}$ & $\begin{array}{c}\text { Shelf life } \\
\text { (months) }\end{array}$ \\
\hline 0 & 63.96 \\
\hline 5 & 46.87 \\
\hline 10 & 34.78 \\
\hline 15 & 26.09 \\
\hline 20 & 19.75 \\
\hline 25 & 15.09 \\
\hline 30 & 11.64 \\
\hline 35 & 9.05 \\
\hline 40 & 7.09 \\
\hline 45 & 5.61 \\
\hline 50 & 4.46 \\
\hline
\end{tabular}

In table (4) we saw the shelf life of pomegranate juice at different temperatures, it was observed that the samples stored at $0 \mathrm{C}^{0}$ has a longer shelf life(63.96 months) than those stored at $50 \mathrm{C}^{0}$ (4.46 months) .when the loss of ascorbic acid was $25 \%$. This mean the shelf life decreased with increasing the temperatures of storage house . This results agrees with other researches as (Paul \& Ghosh, 2012) and (Vikram, Ramesh, \& Prapulla, 2005), which reported that the shelf life of lemon juices when the lost of Ascorbic Acid was $25 \%$ was 84.8 months when the storage temperature is $0 \mathrm{C}^{0}$, but where the the storage temperature is $59 \mathrm{C}^{0}$ the shelf life was 4.01 months.

\section{CONCLUSION}

The Ascorbic acid content of pomegranate juices was 14 $\mathrm{mg} / 100 \mathrm{ml}$. the concentrations of ascorbic acid or Vitamin C or in each specimen were reduced by time in storage house due to storage house temperature. The dissolution of vitamin $\mathrm{C}$ in all specimens of the juices was observed to follow first-order reaction kinetics. The dissolution response rate constants were increased with increasing storage house temperature. They ranged $0.1587,0.2456$ and 0.4585 at $15,25,35 \mathrm{C}^{0}$, respectively. The ascorbic acid content after 4 months was 7, 5 and $2 \mathrm{mg} / 100 \mathrm{ml}$ at storage house time $15,25,35 \mathrm{C}^{0}$ respectively.

The activation energy for the dissolution reaction of vitamin C in pomegranate juice was $21.54 \mathrm{~K} . \mathrm{cal} / \mathrm{mol}$. The half time were decreased with increasing storage house temperature, they ranged 4.2, 2.8 and 1.5 months at storage house temperatures $15,25,35 \mathrm{C}^{0}$ respectively. The temperature coefficients $\left(\mathrm{Q}_{10}\right)$ was 1.55 when the storage house temperature rise from 15 to $25 \mathrm{C}^{0}$ and 1.58 when the temperature rise form 25 to $35 \mathrm{C}^{0}$. The self life of ascorbic acid decrease with increasing the temperatures of storage house .

\section{REFERENCES}

A. Holcroft, Deirdre; \& Gil, M. K. (1998). Effects of CO2 on pomegranete.pdf. 
Aguilar, R., Ramırez, J., Garrote, G., \& Vázquez, M. (2002). Kinetic study of the acid hydrolysis of sugar cane bagasse. Journal of food engineering, 55(4), 309-318.

Awagu, E., Ekanem, E., Kolo, A., \& Adamu, M. (2017). Kinetic modeling of vitamin c (ascorbic acid) degradation in blanched commonly consumed salad vegetables using computer simulation analysis. Journal of Applied Chemistry, 10, 59-66.

Doski, R. I. (2019). Kinetic of Ascorbic Acid Dissolution in local pomegranate Juices. Science Journal of University of Zakho, $7(2)$.

Hasnaoui, N., Jbir, R., Mars, M., Trifi, M., Kamal-Eldin, A., Melgarejo, P., \& Hernandez, F. (2011). Organic acids, sugars, and anthocyanins contents in juices of Tunisian pomegranate fruits. International Journal of Food Properties, 14(4), 741-757.

Laing, B., Schlueter, D., \& Labuza, T. (1978). Degradation kinetics of ascorbic acid at high temperature and water activity. Journal of Food Science, 43(5), 1440-1443.

Lugwisha Esther Hellen, Fabian Christina, \& Othman, O. C. (2014). Determination of Physico-Chemical Properties of Pomegranate (punica granatum L.) Fruits of Dar es Salaam Tanzania. Journal of Food and Nutrition Sciences, 2(6), 277-284. doi:10.11648/j.jfns.20140206.16

Mditshwa, A., Fawole, O. A., Al-Said, F., Al-Yahyai, R., \& Opara, U. L. (2013). Phytochemical content, antioxidant capacity and physicochemical properties of pomegranate grown in different microclimates in South Africa. South African Journal of Plant and Soil, 30(2), 81-90.

N. Matei et al. (2008). Kinetic study of vitamin C dissolution from pharmaceutical products. Rom. Reports Phys., 53(1-2), 343351 .

Nkwocha, A., Ekeke, I., Kamalu, C., Oghome, P., Osoka, E., \& Nkuzinna, O. (2018). Kinetic Modelling of Vitamin C Degradation in Selected Fruits under Market Storage
Conditions. International Journal of Environment, Agriculture and Biotechnology, 3(5), 1618-1627.

Nweze, C., Abdulganiyu, M., \& Erhabor, O. (2015). Comparative analysis of vitamin $\mathrm{C}$ in fresh fruits juice of Malus domestica, Citrus sinensi, Ananas comosus and Citrullus lanatus by iodometric titration. Int. J. Sci. Environ. Technol, 4(1), 17-22.

Ojukwu, U., \& Nwobi, S. (2017). Determination of ascorbic acid content of some local fruits in Nigeria. Analytical Chemistry: An Indian Journal, 17(1), 1-5.

Othman, O. C., \& Mbogo, G. (2009). Physico-chemical characteristics of storage-ripened mango (Mangifera indica L.) fruits varieties of eastern Tanzania. Tanzania Journal of Science, 35(1).

Paul, R., \& Ghosh, U. (2012). Effect of thermal treatment on ascorbic acid content of pomegranate juice. Indian J. Biotechnol., 11(3), 309-313.

R. Vijayaraje, S. Krishi, \& Vidyalaya, V. (2011). Studies on Drying of Garlic ( Allium sativum L .) THESIS Submitted to the Rajmata Vijayaraje Scindia Krishi Vishwa Vidyalaya, Gwalior In partial fulfillment of the requirements for the degree of MASTER OF SCIENCE In HORTICULTURE ( Post Harvest Management,".

Rahmawati, S., \& Bundjali, B. (2012). Kinetics of the oxidation of vitamin C. Indo. J. Chem, 12(3), 291-296.

Robertson, G., \& Samaniego, C. (1986). Effect of initial dissolved oxygen levels on the degradation of ascorbic acid and the browning of lemon juice during storage. Journal of Food Science, 51(1), 184-187.

RODRIGUEZ, P. C., DURAN, Z. V., MURIEL, F. J., \& FRANCO, T. D. (2012). Physico-chemical quality parameters of mango (Mangifera indica L.) fruits grown in a Mediterranean subtropical climate (SE Spain).

Vikram, V., Ramesh, M., \& Prapulla, S. (2005). Thermal degradation kinetics of nutrients in orange juice heated by electromagnetic and conventional methods. Journal of food engineering, 69(1), $31-40$. 